\title{
$\beta$-Lapachone Increases Survival of Septic Mice by Regulating Inflammatory and Oxidative Response
}

\author{
Ana L. de B. Oliveira, ${ }^{1}$ Kely C. Navegantes-Lima, ${ }^{1}$ Valter V. S. Monteiro $\mathbb{D}{ }^{2}$ \\ Lucas B. G. Quadros, ${ }^{3}$ Juliana P. de Oliveira, ${ }^{3}$ Sávio M. dos Santos, ${ }^{4}$ Anna C. A. de A. Pontes, ${ }^{4}$ \\ Gilson P. Dorneles $\mathbb{D}^{5}{ }^{5}$ Pedro R. T. Romão, ${ }^{5}$ Luiz C. R. Júnior, ${ }^{5}$ Alaíde B. de Oliveira, ${ }^{6}$ \\ and Marta C. Monteiro $\mathbb{D D}^{1,3,4}$ \\ ${ }^{1}$ Neuroscience and Cellular Biology Post-Graduation Program, Biology Science Institute, Federal University of Pará/UFPA, \\ Belém 66075-900, Brazil \\ ${ }^{2}$ Center of Research of Inflammatory Diseases, Department of Pharmacology, Ribeirão Preto Medical School, University of São Paulo, \\ Ribeirão Preto 14055230, Brazil \\ ${ }^{3}$ School of Pharmacy, Health Science Institute, Federal University of Pará/UFPA, Belém 66075-900, Brazil \\ ${ }^{4}$ Pharmaceutical Sciences Post-Graduation Program, Institute of Health Sciences, Federal University of Pará/UFPA, \\ Belém 66075-900, Brazil \\ ${ }^{5}$ Laboratory of Cellular and Molecular Immunology, Department of Basic Health Sciences, Federal University of Health Sciences of \\ Porto Alegre, Porto Alegre 90050-170, Brazil \\ ${ }^{6}$ Department of Pharmaceutical Products, Faculty of Pharmacy, Federal University of Minas Gerais, \\ Belo Horizonte 31270-901, Brazil
}

Correspondence should be addressed to Marta C. Monteiro; martachagas2@yahoo.com.br

Received 15 August 2020; Revised 26 October 2020; Accepted 25 November 2020; Published 12 December 2020

Academic Editor: Guodong Zhang

Copyright ( 2020 Ana L. de B. Oliveira et al. This is an open access article distributed under the Creative Commons Attribution License, which permits unrestricted use, distribution, and reproduction in any medium, provided the original work is properly cited.

\begin{abstract}
Sepsis is characterized by a dysregulated immune response to infection characterized by an early hyperinflammatory and oxidative response followed by a subsequent immunosuppression phase. Although there have been some advances in the treatment of sepsis, mortality rates remain high, urging for the search of new therapies. $\beta$-Lapachone ( $\beta$-Lap) is a natural compound obtained from Tabebuia avellanedae Lorentz ex Griseb. with several pharmacological properties including bactericidal, anti-inflammatory, and antioxidant activity. Thus, the aim of this study was to evaluate the effects of $\beta$-Lap in a mouse sepsis model. To this, we tested two therapeutic protocols in mice submitted to cecal ligation and puncture- (CLP-) induced sepsis. First, we found that in pretreated animals, $\beta$-Lap reduced the systemic inflammatory response and improved bacterial clearance and mouse survival. Moreover, $\beta$-Lap also decreased lipid peroxidation and increased the total antioxidant capacity in the serum and peritoneal cavity of septic animals. In the model of severe sepsis, the posttreatment with $\beta$-Lap was able to increase the survival of animals and maintain the antioxidant defense function. In conclusion, the $\beta$-Lap was able to increase the survival of septic animals by a mechanism involving immunomodulatory and antioxidant protective effects.
\end{abstract}

\section{Introduction}

Sepsis is clinically defined as a life-threatening condition of organ dysfunction caused by a dysregulated immune response to infection [1]. In intensive care units (UCI), it is considered the main cause of death especially in patients with comorbid- ities [2]. It is estimated to affect more than 30 million people worldwide every year, mainly in low- and middle-income countries, causing 5 million deaths [3]. In sepsis, early activation of both innate and adaptive immune responses leads to an overwhelming inflammatory response, which comprises fever, refractory shock, inadequate resuscitation, and pulmonary or 
cardiac failure. Meanwhile, mortality at the later period is due to longer immunosuppression with secondary infections resulting in organ injury and/or failure [4]. In the hyperinflammatory phase, immune cells release a great amount of cytokines and reactive oxygen species, causing tissue damage, neutrophil paralysis, severe oxidative stress, and multiple organ failure cellular [5]. In fact, some studies have reported the role of oxidative stress in the pathogenesis and mortality of patients and animals with cecal ligation and puncture(CLP-) induced polymicrobial sepsis $[6,7]$.

The drugs currently available for the treatment of sepsis are often unsatisfactory [8]. In the last decades, there has been a renewed interest in natural products as a source of new drugs, including immunomodulatory substances $[6,9]$. In this context, we have shown successful strategies for the treatment of CLP-induced septic mice by means of substances/compounds with immunomodulatory and counterregulatory antioxidant and anti-inflammatory actions $[6,7,9]$. In this sense, $\beta$-Lap is a naturally occurring lipophilic naphthoquinone originally obtained from the heartwood of the lapacho tree (Tabebuia avellanedae Lorentz ex Griseb.) native from South America [10]. This quinone is one of the most important lapachol derivatives and has been studied for its interesting chemical and biological properties, such as anticancer [11], trypanocidal [12], bactericidal and fungicidal [13-15], anti-inflammatory [16-18], and antioxidant [19] activities. The mechanisms of $\beta$-Lap include inhibition in the expression of inducible nitric oxide synthase (iNOS), prostaglandin E2 (PGE2), and proinflammatory cytokines such tumor necrosis factor alpha (TNF- $\alpha$ ) and interleukin-6 (IL-6) and increase in the expression of anti-inflammatory molecules such as interleukin-10 (IL-10) $[16,20]$.

Therefore, considering the current problems related to the treatment of sepsis and the urgency for new therapeutic alternatives, we investigated for the first time the effects of prophylactic and therapeutic administration in CLP-induced polymicrobial sepsis in mice.

\section{Materials and Methods}

2.1. Ethics Statement. The protocols used in this study were approved by the Institutional Animal Ethics Committee of the Federal University of Pará/UFPA (CEUA, Protocol: 1912080716) and carried out in accordance with recommendations of the Guide for the Care and Use of Laboratory Animals of the Brazilian National Council of Animal Experimentation (http://www.sbcal.org.br/) and the NIH Guidelines for the Care and Use of Laboratory Animals.

2.2. Mice. Male Swiss mice (6-8 weeks old) were obtained from the Animal Facility of the UFPA and housed under standard conditions $\left(22^{\circ} \mathrm{C}, 12 \mathrm{~h}\right.$ light $/ 12 \mathrm{~h}$ dark cycle) with food and water ad libitum in groups of 5 per cage $(41 \cdot 34 \cdot 16 \mathrm{~cm})$ in the animal facility of the School of Pharmacy from UFPA, for at least three days before experiments.

2.3. Preparation of $\beta$-Lap. The isolated compound $\beta$-Lap was kindly donated by Dr. Alaide Braga de Oliveira from the Pharmacy Faculty of the Federal University of Minas Gerais
(UFMG). $\beta$-Lap (3,4-dihydro-2,2-dimethyl-2H-naphthol[1,2b]pyran-5,6-dione) was synthesized from naturally occurring lapachol derived from $T$. avellanedae (Bignoneaceae) using sulfuric acid according to a method from Hooker [21]. The solubilization of $\beta$-Lap was performed in dimethyl sulfoxide (DMSO) at $20 \mathrm{mg} / \mathrm{mL}$ stored at $-20^{\circ} \mathrm{C}$ and diluted in saline immediately before use for pretreatment $(50 \mathrm{mg} / \mathrm{kg})$ and posttreatment (1 and $5 \mathrm{mg} / \mathrm{kg})$ [10].

2.4. Experimental Design and Moderate and Severe CLP Models. The polymicrobial sepsis was induced using the CLP model according to de Souza Gomes et al. Briefly, animals were anesthetized with intraperitoneal injection of $200 \mu \mathrm{L}$ of ketamine $(100 \mathrm{mg} / \mathrm{kg})$ and xylazine $(10 \mathrm{mg} / \mathrm{kg})$ solution, a small one-centimeter laparotomy was performed, and the cecum was exposed and then ligated using a 3-0 silk suture [6]. To induce a moderate severity of CLP, the cecum was punctured one single time with a 22-gauge needle, while severe CLP was induced with two perforations using an 18gauge needle [22]. In protocols, the cecum was gently squeezed to extrude a small amount of fecal content and was left to its original position in the abdominal cavity. Sham-operated mice underwent the same procedure, except for ligation and perforation of the cecum. The abdominal wall was closed, and fluid resuscitation was conducted with subcutaneous injection of $1 \mathrm{~mL}$ of saline $0.9 \%$ [6].

2.4.1. $\beta$-Lap in Pretreatment. The moderate CLP animals were divided into 4 groups: (1) sham, (2) CLP+saline (0.9\%), (3) CLP+ $\beta$-Lap (50 mg/kg), and (4) CLP+ceftriaxone $(20 \mathrm{mg} / \mathrm{kg}$; ABL, Brasil). All treatments of the animals were administered intraperitoneally in a volume of $100 \mu \mathrm{L} 24 \mathrm{~h}$ before and right after the moderate CLP. In the first experiment, the survival of 28 mice (7 per group) was evaluated. The ceftriaxone group was added as a control, for being an antibiotic that acts against a wide range of pathogens being and used in the prophylaxis of infection and ensuring a longer survival in CLP models $[6,23]$. Survival animals were monitored for 12 days (Figure 1(a)). In the second experiment, the anti-inflammatory and antioxidant parameters of 15 mice ( 5 per group) were evaluated. The animals were then euthanized 12 and 24 hours after surgery, and samples of blood, plasma, and peritoneal fluid lavage were collected and stored at $-20^{\circ} \mathrm{C}$ until analysis (Figure $1(\mathrm{~b})$ ).

2.4.2. $\beta$-Lap in Posttreatment. The severe CLP animals were divided into 5 groups: (1) sham, (2) CLP+saline (0.9\%), (3) $\mathrm{CLP}+\beta$-Lap $(5 \mathrm{mg} / \mathrm{kg}),(4) \mathrm{CLP}+\beta$-Lap $(1 \mathrm{mg} / \mathrm{kg})$, and (5) CLP+ertapenem (30 mg/kg; Merck Research Laboratory, Whitehouse Station, NJ, USA) (Figure 1(b)). All treatments of the animals were administered intraperitoneally in a volume of $100 \mu \mathrm{L}$ beginning 6 hours after severe CLP and $12 / 12$ hours after the first treatment. In the first experiment, the survival of 35 mice (7 per group) was evaluated, and the ertapenem group was added as a control for being an antibiotic with a broad spectrum and used in hospitalized patients with serious infections and increased survival in CLP [24, 25]. The treatment of survival animals remained until the 4 th day for group CLP+ertapenem and the $7^{\text {th }}$ day for the 


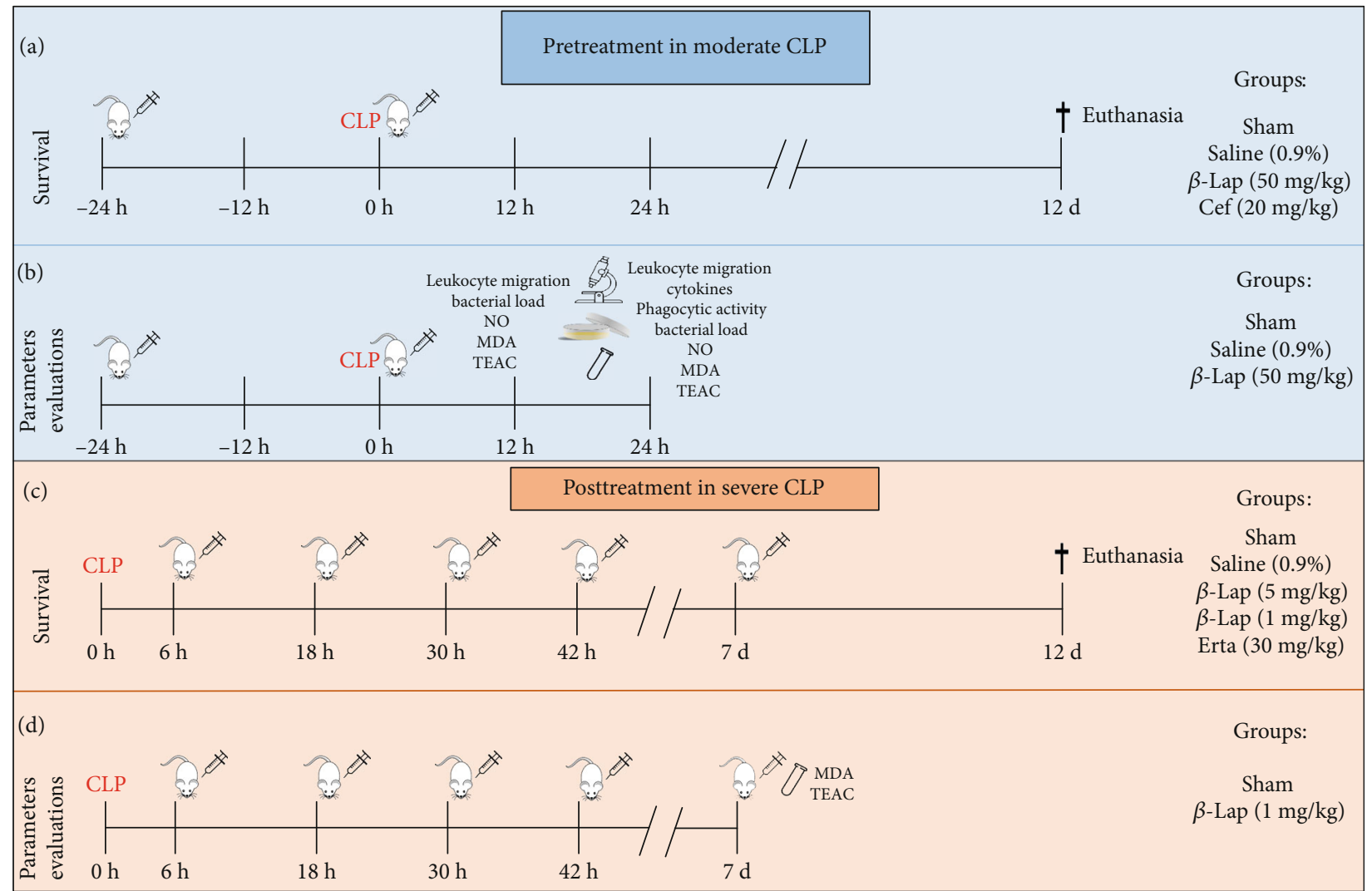

Figure 1: Experimental sets of pretreatment and posttreatment of CLP-induced septic mice with $\beta$-lapachone. CLP: cecal ligation and puncture; $\beta$-Lap: $\beta$-lapachone; CEF: ceftriaxone; NO: nitric oxide; MDA: malondialdehyde; TEAC: Trolox Equivalent Antioxidant Capacity; Erta: ertapenem.

other treatments (CLP+saline and CLP+ $\beta$-Lap groups). The survival of the animals was evaluated for 12 days (Figure 1(c)). In the second experiment, the antioxidant parameters of 10 mice (sham and CLP+ $\beta$-Lap $1 \mathrm{mg} / \mathrm{kg}, 5$ per group) were evaluated. The animals were euthanized 7 days after surgery and 6 hours before the last treatment to collect samples of serum and peritoneal fluid lavage and stored at $-20^{\circ} \mathrm{C}$ until analysis (Figure $1(\mathrm{~d})$ ).

2.5. Survival and Weight Analysis. After CLP induction, the survival of animals (7 mice per group) was monitored each $12 \mathrm{~h}$ for 12 consecutive days, and mice were weighted as a parameter of general health. To reduce suffering, mice presenting signs of imminent death (i.e., ataxia, inability to maintain an upright position, tremor, and/or agonal breathing) were euthanized by ketamine/xylazine $(>100 / 10 \mathrm{mg} / \mathrm{kg}$, sc) overdose. The animals that survived for longer than 12 days were euthanized. The survival rate and weight were calculated followed by delineation of survival and weight curve.

2.6. Leukocyte Recruitment to the Peritoneal Cavity. After 12 and $24 \mathrm{~h}$ of CLP induction in pretreatment groups, the mice were euthanized under ketamine/xylazine, and the peritoneal cavity cells were harvested by washing the cavity with $3 \mathrm{~mL}$ of Phosphate-Buffered Saline (PBS) (Sigma-Aldrich, St. Louis, MO, USA) containing ethylenediaminetetraacetic acid (EDTA; NewProv) $1 \mathrm{mM}$. The recovered volumes were sim- ilar in all animals of each experimental group. The total number of leukocytes was determined using a Neubauer chamber, and differential cell counts were carried out on cytocentrifuge (Coulter ${ }^{\circledR}$ ACT; Coulter Corporation, Miami, Florida, USA) slides stained with panotic (Laborclinltda, Pinhais-SP, Brasil). The results are presented as the number of neutrophils and mononuclear cells per cavity.

2.7. Phagocytic Activity of Peritoneal Macrophages. The phagocytic capacity of peritoneal macrophages of septic and sham mice was evaluated as previously described. Peritoneal macrophages from sham, CLP-saline, and CLP- $\beta$-Lap pretreatment groups were collected 24 post moderate sepsis induction and incubated in a 96-well microplate $\left(2 \times 10^{5}\right.$ cells/well) for $40 \mathrm{~min}$ at $37^{\circ} \mathrm{C}$ and $5 \%$ carbon dioxide $\left(\mathrm{CO}_{2}\right)$. Two hours later, adherent cells were incubated with $10 \mu \mathrm{L}$ of neutral-red stained zymosan (Sigma-Aldrich, St. Louis, MO, USA) $\left(1 \times 10^{8}\right.$ particles $\left./ \mathrm{mL}\right)$, and after $30 \mathrm{~min}$, the supernatants were removed and cells fixed with Baker's formol-calcium ( $4 \%$ formaldehyde, $2 \%$ sodium chloride, and $1 \%$ calcium acetate) for $30 \mathrm{~min}$. Following, the cells were washed two times by centrifugation in PBS ( $450 \mathrm{~g}$ for $5 \mathrm{~min}$ ). After solubilization of neutral-red stain with $0.1 \mathrm{~mL}$ of acidified alcohol (10\% acetic acid, $40 \%$ ethanol in distilled water), the absorbance was measured in a microplate reader at $550 \mathrm{~nm}$ [26]. 
2.8. Cytokine Measurement. The levels of TNF- $\alpha$ and interleukin-1 beta (IL-1 $\beta$ ) in serum and peritoneal fluid collected at $24 \mathrm{~h}$ post-CLP induction, in the pretreatment groups, were quantified by Enzyme-Linked Immunosorbent Assay (ELISA) using an appropriate commercial kit (R\&D Systems, Minneapolis, Canada) according to the manufacturer's instructions. The detection limits of each cytokine were IL- $1 \beta, 12.5-800 \mathrm{pg} / \mathrm{mL}$ with sensitivity of $4.8 \mathrm{pg} / \mathrm{mL}$ and TNF- $\alpha, 10.9-700 \mathrm{pg} / \mathrm{mL}$ with sensitivity of $7.21 \mathrm{pg} / \mathrm{mL}$.

2.9. Determination of Nitric Oxide (NO) Production. The nitrite $\left(\mathrm{NO}_{2}\right)$ levels were determined colorimetrically using the Griess method according to Romão et al. [27]. After 12 and 24 hours of the CLP induction, nitrite level was determined in $100 \mu \mathrm{L}$ of samples (serum and lavage peritoneal) from the pretreatment groups incubated with an equal volume of Griess reagent for $10 \mathrm{~min}$ at room temperature. The absorbance was measured on a plate scanner (Spectra Max 250; Molecular Devices, Menlo Park, CA, USA) at $550 \mathrm{~nm}$. The nitrite concentration was determined using a standard curve generated using sodium nitrate (NaNO2) and expressed as $\mu \mathrm{Mol} / \mathrm{mL}$.

2.10. Bacterial Load Determination. The colony-forming units (CFU) in blood and peritoneal fluid of pretreatment mice were determined 12 and $24 \mathrm{~h}$ after CLP induction. An amount of $10 \mu \mathrm{L}$ of samples was diluted with sterile PBS $1: 10$, and then, $10 \mu \mathrm{L}$ of each dilution was cultured in Müller Hinton Agar and incubated at $37^{\circ} \mathrm{C}$ for $24 \mathrm{~h}$. The colonies were counted and expressed in $\mathrm{CFU} / \mathrm{mL}$.

2.11. Measurement of Malondialdehyde (MDA) Levels. Lipid peroxidation was measured in serum and peritoneal fluid of septic animals from the pretreatment (12 and $24 \mathrm{~h}$ after PLC induction) and posttreatment (7 days postsurgery) groups using thiobarbituric acid reactive substance (TBARS; Sigma-Aldrich, St. Louis, MO, USA) assay. An aliquot of $100 \mu \mathrm{L}$ of the samples was mixed with $0.05 \mathrm{M}$ trichloroacetic acid (TCA; Sigma-Aldrich, St. Louis, MO, USA) and 0.67\% thiobarbituric acid (TBA; Sigma-Aldrich, St. Louis, MO) in $2 \mathrm{M}$ sodium sulfate and heated in a water bath at $94^{\circ} \mathrm{C}$ for $90 \mathrm{~min}$. The chromogen formed was extracted in n-butanol and measured at $535 \mathrm{~nm}$. An MDA standard solution was used to construct a standard curve against which unknown samples were plotted. Results are expressed as malondialdehyde equivalents in nmol/L [28].

2.12. Trolox Equivalent Antioxidant Capacity (TEAC) Assay. The total antioxidant capacity (TAC) of serum and peritoneal fluid samples of septic mice from the pretreatment (12 and $24 \mathrm{~h}$ after PLC induction) and posttreatment (7 days postsurgery) groups was evaluated by $( \pm$ )-6-hydroxy-2,5,7,8tetramethylchromane-2-carboxylic acid (Sigma-Aldrich, St. Louis, MO, USA) equivalent antioxidant capacity assay. In this assay, 2,2' -azino-bis(3-ethylbenzothiazoline-6-sulfonic acid) diammonium salt (ABTS) (Sigma-Aldrich, St. Louis, MO, USA) was incubated with potassium persulphate (SigmaAldrich, St. Louis, MO, USA) to produce $\mathrm{ABTS}^{+}$, a green/blue chromophore. The inhibition of $\mathrm{ABTS}^{+}$formation by antioxidants in the samples was expressed as Trolox equivalents, determined at $740 \mathrm{~mm}$ using a calibration curve plotted with different amounts of Trolox (Sigma-Aldrich, St. Louis, MO, USA) [29].

2.13. Statistical Analysis. Statistical analyses were performed using the GraphPad Prism 6 software (GraphPad Software Inc., La Jolla, USA). Data are expressed as the mean SD values. Statistically significant differences between groups were determined using analysis of variance (ANOVA) followed by Tukey multiple comparison tests. Survival differences were assessed using the Kaplan-Meier analysis followed by a logrank test. In all cases, the significance level adopted was 5\% $(p<0.05)$.

\section{Results}

3.1. $\beta$-Lap Pretreatment Increased Mononuclear Cell Recruitment and Phagocytosis and Improved Survival of Septic Mice. In the moderate CLP model, saline-pretreated septic animals (saline-CLP) survived for 5 days, while $100 \%$ of $\beta$-Lap-pretreated CLP mice ( $\beta$-Lap-CLP) survived up to 12 days after sepsis induction and $60 \%$ of ceftriaxone pretreated animals died until the seventh day (Figure 2(a)). The body weight was monitored in order to evaluate the general health condition of animals. As shown in Figure 2(b), all animals presented a drop in body weight after sepsis induction. However, in animals pretreated with $\beta$-Lap, weight loss was significantly delayed. Regarding leukocyte recruitment towards infectious focus, there was a significant increase in neutrophils and mononuclear cell infiltration into the peritoneal cavity at 12 and $24 \mathrm{~h}$ in saline-pretreated septic mice. However, the pretreated with $\beta$-Lap partially inhibited the neutrophil recruitment at $24 \mathrm{~h}$, while caused a significant increase in mononuclear migration at both 12 and $24 \mathrm{~h} \mathrm{com-}$ pared to the saline group (Figure 2(c)). The phagocytic capacity of peritoneal cells of septic animals was elevated at $24 \mathrm{~h}$, and the pretreatment with $\beta$-Lap potentiated this activity (Figure 2(d)).

3.2. $\beta$-Lap Pretreatment Decreased Inflammatory Cytokines and Bacterial Load. Considering the inflammatory pathological response in sepsis, septic mice exhibited higher levels of IL- $1 \beta$ and TNF- $\alpha$ in serum and peritoneal cavity within $24 \mathrm{~h}$ after sepsis induction (Figures 3(a)-3(d)). In contrast, $\beta$-Lap pretreatment was able to inhibit the production of these cytokines in both sites. Regarding NO, this inflammatory mediator increased in serum and peritoneal cavity of saline-treated septic animals at 12 and $24 \mathrm{~h}$ in relation to control animals, while the $\beta$-Lap-CLP group showed a significant reduction in systemic NO levels with a concomitant increase in peritoneal cavity within $24 \mathrm{~h}$ (Figures $3(\mathrm{e})$ and $3(\mathrm{f})$ ). In addition, the pretreatment of animals with $\beta$-Lap induced a complete bacterial clearance in blood and peritoneal cavity within $24 \mathrm{~h}$ (Figures $3(\mathrm{~g})$ and $3(\mathrm{~h})$ ).

3.3. B-Lap Pretreatment Shows Antioxidant Action with Increased TEAC Levels and Decreased Oxidative Marker in Fluids. The levels of lipid peroxidation, indicative of oxidative damage, were elevated in saline-CLP mice in serum and peritoneal fluid at 12 and $24 \mathrm{~h}$ postinduction. The pretreatment 


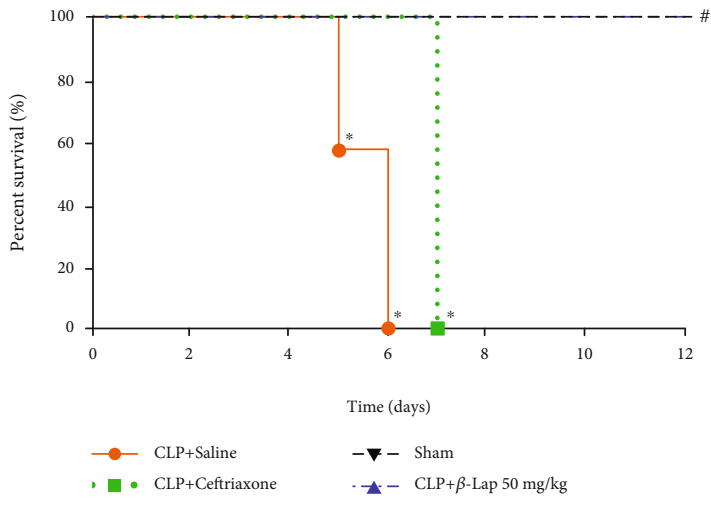

(a)

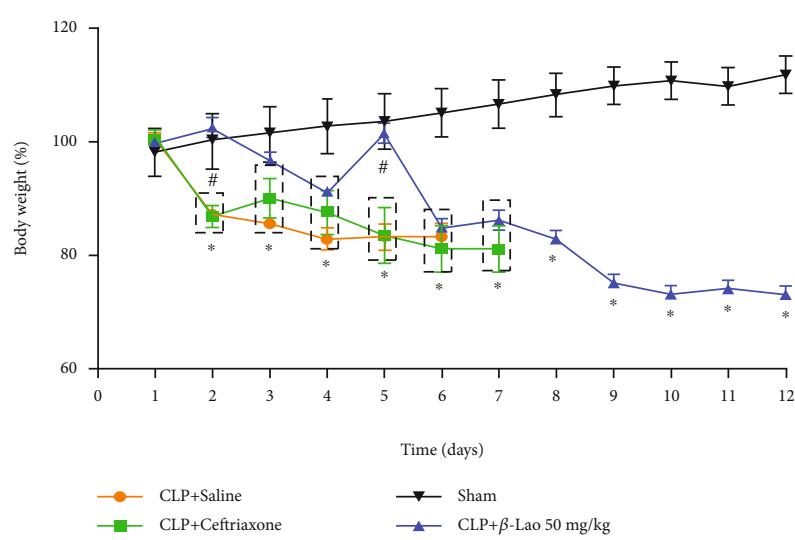

(b)

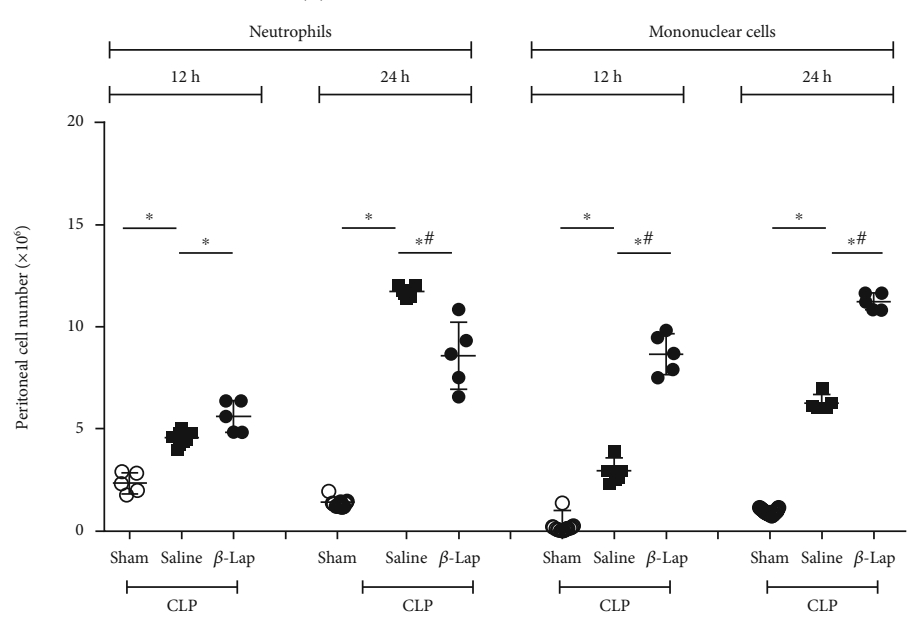

(c)

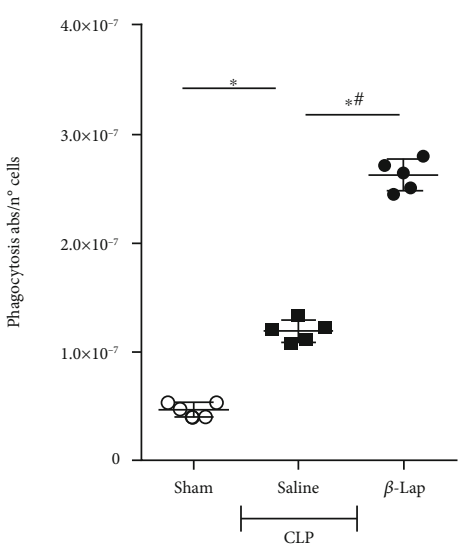

(d)

Figure 2: $\beta$-Lap pretreatment increases septic mouse survival and stimulates mononuclear cell recruitment and phagocytosis. (a) The survival rate of septic mice from saline, $\beta$-Lap $(50 \mathrm{mg} / \mathrm{kg})$, and ceftriaxone $(20 \mathrm{mg} / \mathrm{kg})$ groups. (b) Body weight changes. (c) Leukocyte recruitment to infection site at 12 and $24 \mathrm{~h}$ post-CLP. (d) The phagocytic capacity of peritoneal cells $24 \mathrm{~h}$ after CLP. ${ }^{*} p<0.05$ vs. sham; ${ }^{\#} p<0.05$ vs. saline-CLP.

with $\beta$-Lap was able to reduce MDA levels at both sites (Figures 4(a) and 4(b)). Regarding antioxidant capacity, septic animals pretreated with saline showed a reduction in TEAC levels in the peritoneal cavity and serum at 12 and $24 \mathrm{~h}$, while the CLP- $\beta$-Lap group showed high levels of total antioxidant capacity (Figures 4 (c) and 4(d)).

Table 1 shows the MDA/TEAC ratios in peritoneal fluid and serum at 12 and $24 \mathrm{~h}$ post-CLP, confirming that salinepretreated septic animals had high oxidative status and that the pretreatment with $\beta$-Lap lead to a significant reduction in this oxidative profile.

\section{4. $\beta$-Lap Posttreatment Improved the Survival Rate of Severe} Septic Mice and Restored Basal MDA and TEAC Levels. All severe septic mice posttreated with saline died within 3 days. However, the posttreatment with $\beta$-Lap was able to increase the survival of animals up to 12 days, reaching 60 and $50 \%$ survival rate at doses of 1 and $5 \mathrm{mg} / \mathrm{kg}$, respectively. On the other hand, ertapenem also increased the survival of animals with severe sepsis, reaching $54 \%$ survival on day 12 after sepsis (Figure 5(a)). Moreover, we found that septic animals treated with $\beta$-Lap $(1 \mathrm{mg} / \mathrm{kg})$ showed decreased levels of
MDA in serum and peritoneal fluid at the $7^{\text {th }}$ day of sepsis compared to the moderate CLP group at $24 \mathrm{~h}$ postinduction (Figures 5(b) and 5(c)). Furthermore, $\beta$-Lap-treated severe septic animals also presented higher TEAC values compared to animals with moderate sepsis saline-treated at $24 \mathrm{~h}$ of infection (Figures 5(d) and 5(e)).

Therefore, Table 2 shows that there is no significant difference in oxidative status between sham and $\beta$-Lap groups.

\section{Discussion}

In the present study, we showed for the first time the protective effect of $\beta$-Lap in an experimental sepsis model. The prophylactic treatment with $\beta$-Lap improved the survival of mice in a model of moderate sepsis, regulating neutrophils and mononuclear cell infiltration into the peritoneal cavity and improving phagocytic capacity. $\beta$-Lap showed immunomodulatory actions reducing proinflammatory cytokines (IL- $1 \beta$ and TNF- $\alpha$ ) and NO production in the serum, with a concomitant increase in NO production and bacteria killing in the peritoneal cavity. This protective effect was accompanied by a reduction in lipid peroxidation and an augment 


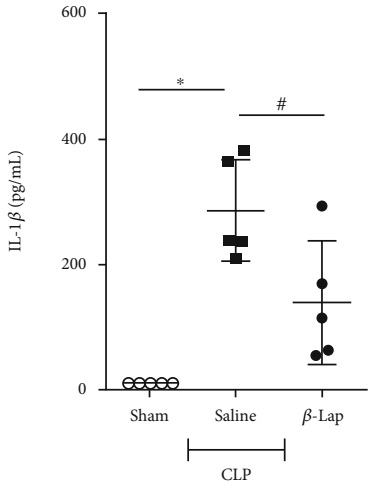

(a)

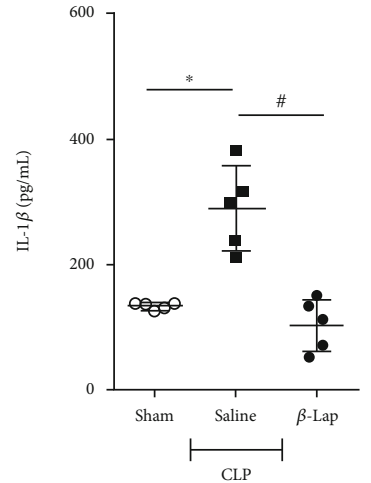

(b)

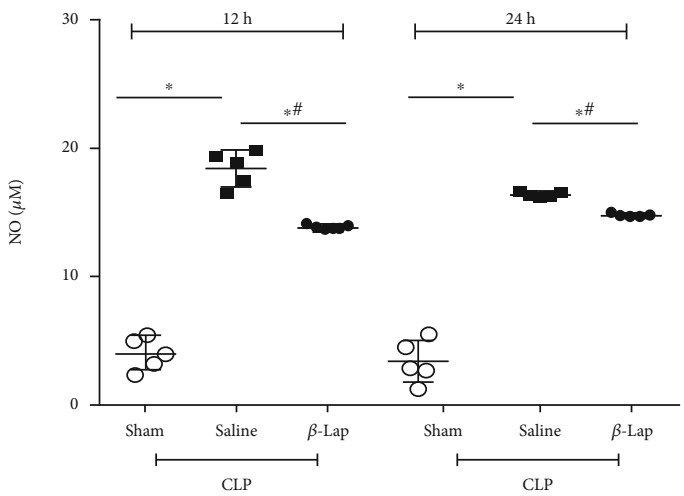

(e)

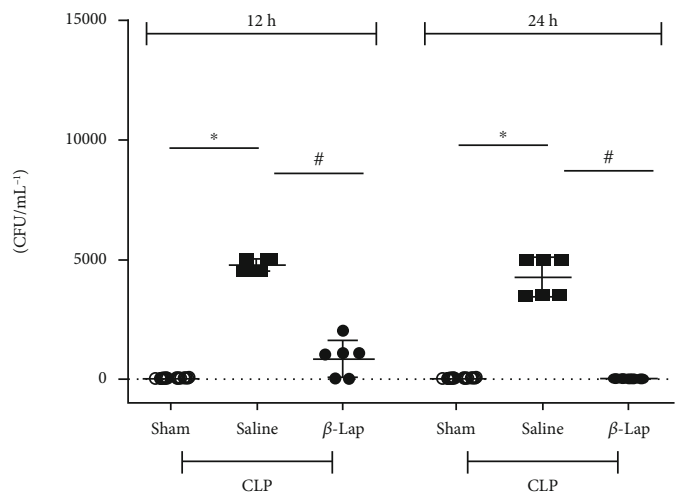

(g)

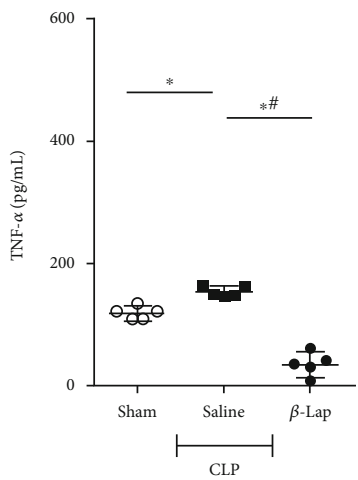

(c)

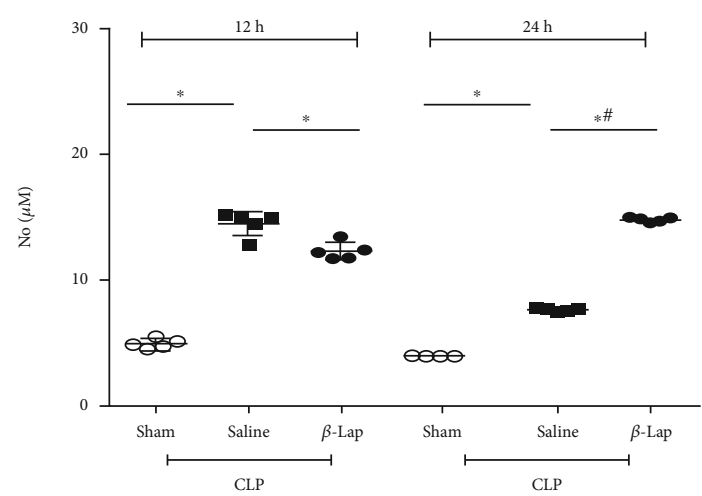

(f)

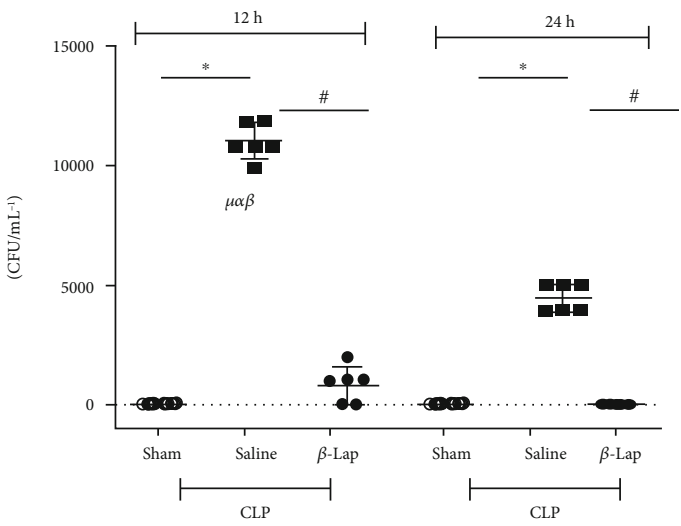

(h)

FIGURE 3: $\beta$-Lap pretreatment inhibits inflammatory cytokines and bacterial load but does not inhibit nitric oxide in the blood of septic animals. The concentrations of IL-1 $\beta$ in the serum (a) and in peritoneal lavage (b) as well as TNF- $\alpha$ in the serum (c) and in peritoneal lavage (d) $24 \mathrm{~h}$ after CLP. Nitric oxide levels in serum (e) and in peritoneal lavage (f) $12 \mathrm{~h}$ and $24 \mathrm{~h}$ after CLP. Bacterial counts (CFUs) in blood (g) and in peritoneal lavage (h). ${ }^{*} p<0.05$ vs. sham; ${ }^{*} p<0.05$ vs. CLP.

in the antioxidant status. On the other hand, the posttreatment with $\beta$-Lap in the severe sepsis model was able to improve the survival rate of septic animals by a mechanism that involves the maintenance of antioxidant defense.

$\beta$-Lap is a bioreductive prodrug that undergoes a reduction of two electrons via nicotinamide adenine dinucleotide phosphate $(\mathrm{NAD}(\mathrm{P}) \mathrm{H})$ quinone oxidoreductase 1 (NQO1). The reduced form of $\beta$-Lap is unstable and therefore is quickly oxidized to the original form of $\beta$-Lap, creating a futile cycle between the oxidized and reduced forms with the production of reactive oxygen species (ROS), such as superoxide anion $\left(\mathrm{O}_{2}^{--}\right)$and hydrogen peroxide $\left(\mathrm{H}_{2} \mathrm{O}_{2}\right)$ [30]. This compound can cause toxicity due to the subsequent depletion of nicotinamide adenine dinucleotide (NADH) or NAD (P) H, catalyzed by NQO1, together with the signal transduction of the oxidative stress trigger by cell death [31]. In fact, the compound has been reported as a promising antitumor candidate drug, since the cytotoxicity of $\beta$-Lap can selectively kill cancer [32].

The selectivity of this compound for tumors is associated with the fact that cancer cells generally have higher NQO1 compared to normal cells [32]. However, specificity and 


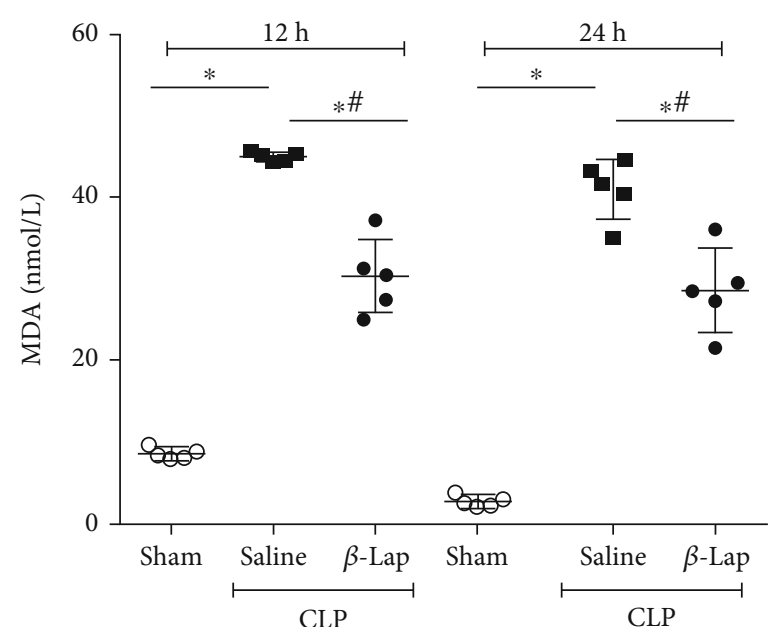

(a)

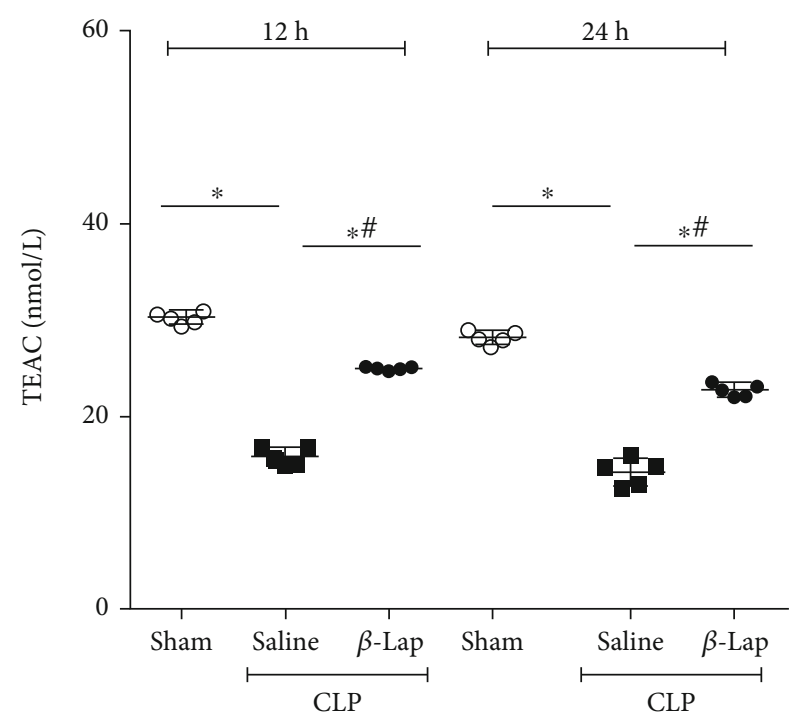

(c)

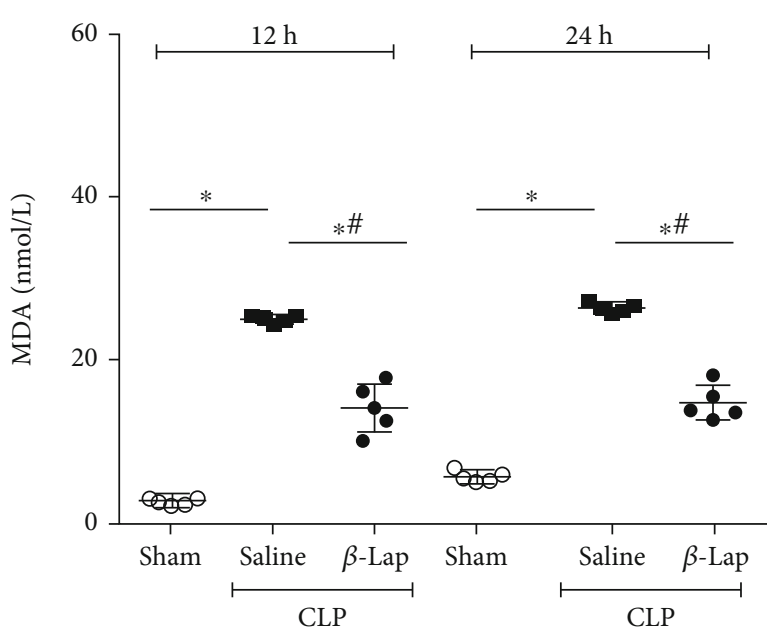

(b)

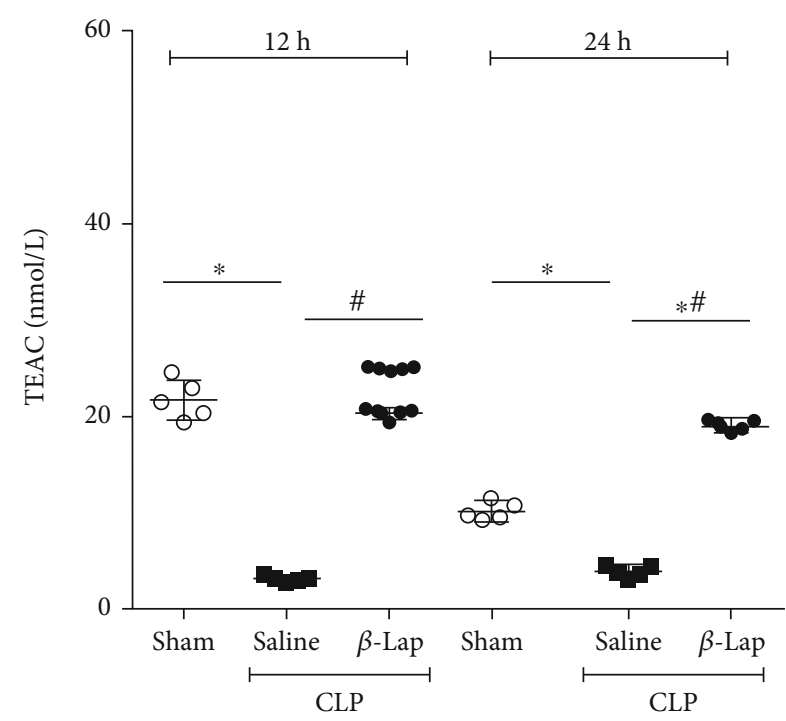

(d)

FIGURE 4: $\beta$-Lap pretreatment shows antioxidant action by increasing TEAC levels and decreasing MDA in septic animals. MDA levels in the serum (a) and peritoneal fluid (b) at 12 and $24 \mathrm{~h}$ post-CLP. TEAC levels in the serum (c) and in peritoneal fluid (d) at 12 and $24 \mathrm{~h}$ post-CLP. ${ }^{*} p<0.05$ vs. sham; ${ }^{*} p<0.05$ vs. saline-CLP.

TABLE 1: Ratios between MDA levels and antioxidant (TEAC) factor of groups 12 and 24 hours after surgery.

\begin{tabular}{|c|c|c|c|c|c|c|}
\hline \multirow[b]{2}{*}{ Time } & \multicolumn{6}{|c|}{$\mathrm{MDA} / \mathrm{TEAC}$ mean $\pm \mathrm{SD}$} \\
\hline & Sham & $\begin{array}{c}\text { Serum } \\
\text { Saline+CLP }\end{array}$ & $\beta$-Lap+CLP & Sham & $\begin{array}{l}\text { Peritoneal lavage } \\
\text { Saline+CLP }\end{array}$ & $\beta$-Lap+CLP \\
\hline $12 \mathrm{~h}$ & $0.18 \pm 0.10$ & $2.51 \pm 0.62^{*}$ & $1.16 \pm 0.43^{* \#}$ & $0.12 \pm 0.01$ & $8.00 \pm 1.09^{*}$ & $0.68 \pm 0.22^{* \#}$ \\
\hline $24 \mathrm{~h}$ & $0.09 \pm 0.04$ & $2.86 \pm 0.95^{*}$ & $1.26 \pm 0.50^{* \#}$ & $0.41 \pm 0.22$ & $7.19 \pm 0.12^{*}$ & $0.76 \pm 0.15^{* \#}$ \\
\hline
\end{tabular}

${ }^{*} p<0.05$ in relation to the sham group; ${ }^{\#} p<0.05$ in relation to the saline-CLP group.

selectivity for NQO1 depend on cytotoxicity that can be achieved only within a relatively short dose range and within a short period of time [33]. The chronic exposure of mice to the compound can produce unpredictable toxic effects in high doses, time, and frequency of exposure [34]. In order to prevent possible toxicity, given that there is a higher frequency of administration and for a longer time considering a possible clinical usage, we sought to evaluate if lower doses would be effective in a longer period of time in the posttreatment of the CLP. Thus, we evaluated the response of prophylactic treatment of $\beta$-Lap in the model of moderate sepsis with a dose of $50 \mathrm{mg} / \mathrm{kg}$ and the posttreatment effect using a model of severe sepsis and a lower dose of $\beta$-Lap $(1 \mathrm{mg} / \mathrm{kg}$ and $5 \mathrm{mg} / \mathrm{kg}$ ). 


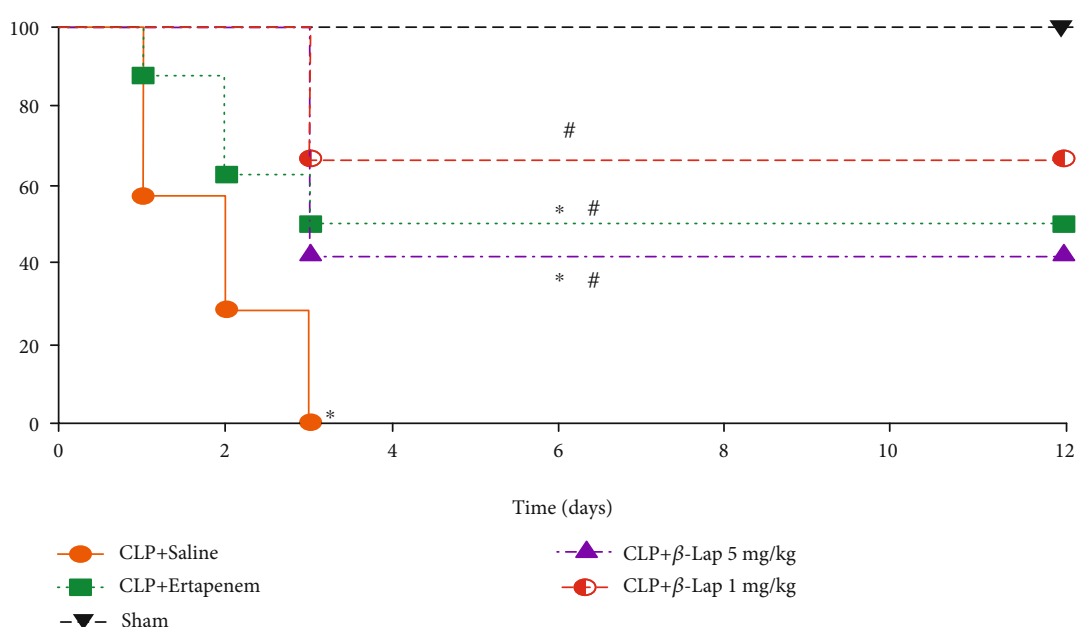

(a)

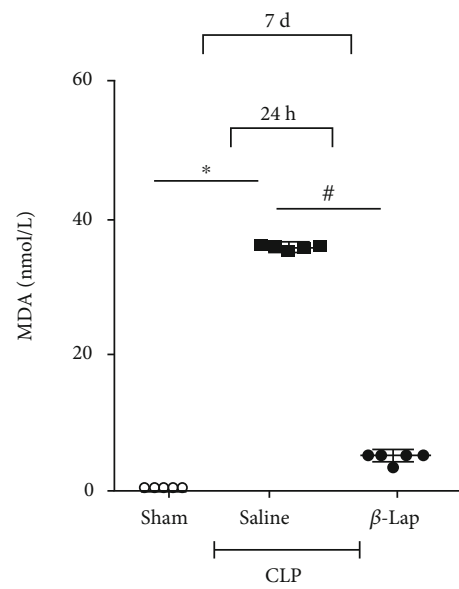

(c)

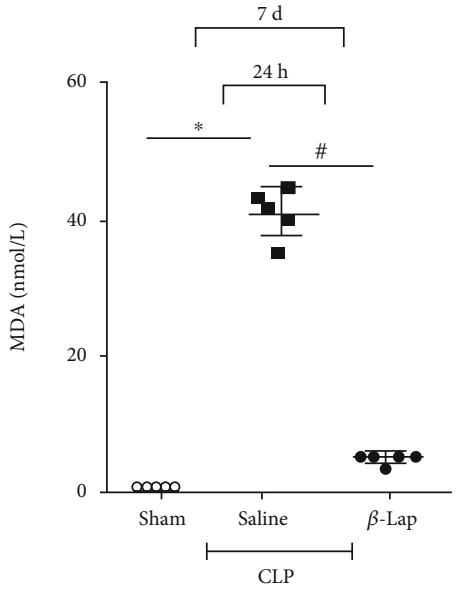

(b)

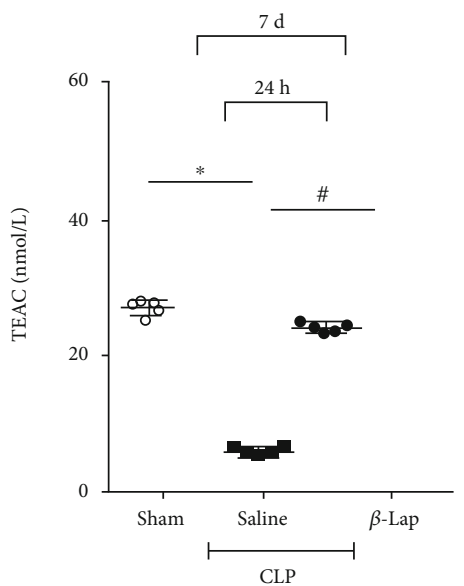

(e)

FIGURE 5: $\beta$-Lap posttreatment improves survival of severe septic mice and restores basal MDA and TEAC levels. (a) The survival rate of septic mice from saline, $\beta$-Lap $(1 \mathrm{mg} / \mathrm{kg} / 5 \mathrm{mg} / \mathrm{kg})$, and ertapenem $(30 \mathrm{mg} / \mathrm{kg})$ groups. The MDA level rate of septic mice from saline $(24 \mathrm{~h}$ post-CLP) and $\beta$-Lap (1 mg/kg), ertapenem $(30 \mathrm{mg} / \mathrm{kg})$ groups 7 days after surgery in the serum (b) and peritoneal lavage (c) TEAC levels of septic mice from saline ( $24 \mathrm{~h}$ post-CLP) and $\beta$-Lap $(1 \mathrm{mg} / \mathrm{kg})$, ertapenem $(30 \mathrm{mg} / \mathrm{kg})$ groups 7 days after surgery in the serum $(\mathrm{d})$ and in peritoneal lavage (e) 7 days after surgery. ${ }^{*} p<0.05$ vs. sham; ${ }^{\#} p<0.05$ vs. CLP.

In sepsis, phagocytic cells are recruited to the site of infection in the initial phase of infection. Neutrophils are the first cells to be recruited and exert potent antimicrobial activity through ROS, reactive nitrogen species (RNS), or granule proteins, which act in support to the microbial killing in phagosome [35, 36]. In addition to phagocytosis, neutrophils act through the formation of networks of extracellular traps (NETs) composed of deoxyribonucleic acid (DNA), histones, antimicrobial proteins, and oxidizing enzymes that are released to trap microbes [37]. The participation of reactive species such as NO is essential for bacteria killing, and its absence can lead to uncontrolled infections, despite the improvement of cell migration to the infectious focus [37]. In this model of moderate sepsis, prophylactic treatment with $\beta$-Lap increased in $12 \mathrm{~h}$ after CLP neutrophil recruitment to the peritoneum, the focus of infection in CLP sepsis and subsequent bacterial growth is better controlled, and survival significantly improved. On the other hand, in our model of severe sepsis and posttreatment with $\beta$-Lap at a dose of
$1 \mathrm{mg} / \mathrm{kg}$, no change inflammatory parameters such as cytokines, mononuclear recruitment, and phagocytosis (unpublished data) were compared to saline-posttreated sepsis animals.

Although essentials for eradicating a wide range of pathogens in the early stages of infection, neutrophil recruitment and overactivation can induce inflammation and deleterious immune responses [5]. The emigrating of neutrophils from the bloodstream can cause tissue and endothelial damage, inducing thrombosis and edema by releasing oxidant compounds, proteases, and cytokines [38]. We found that $24 \mathrm{~h}$ after CLP, the prophylactic treatment with $\beta$-Lap was able to reduce neutrophil recruitment. The transgenic zebrafish model was also observed that the $\beta$-Lap compound caused reduced recruitment of neutrophils to the injury site, without affecting the resolution of inflammation [39]. Moreover, it was demonstrated that the topical treatment of Leishmania major-infected $\mathrm{BALB} / \mathrm{c}$ mice with $\beta$-Lap loaded in lecithinchitosan nanoparticles downregulated IL-1 $\beta$ and 
TABLE 2: Ratios between MDA levels and antioxidant (TEAC) factor of groups 7 days after surgery.

\begin{tabular}{lccccc}
\hline & & \multicolumn{2}{c}{ MDA/TEAC mean \pm SD } & \multicolumn{2}{c}{ Peritoneal lavage } \\
Time & Sham & Saline+CLP & $\beta$-Lap+CLP & Sham & Saline+CLP
\end{tabular}

${ }^{8}$ Saline-CLP group $24 \mathrm{~h} ;{ }^{*} p<0.05$ in relation to the sham group; ${ }^{*} p<0.05$ in relation to the saline-CLP group.

cyclooxygenase (COX-2) in the draining lymph nodes and reduced the cutaneous lesion size and neutrophil infiltration, without affecting parasites burdens [40].

During sepsis progression, neutrophil can decrease phagocytosis, ROS production, and granular activity [37]. In this study, prophylactic treatment with $\beta$-Lap maintained the neutrophil activity observed by the increase in phagocytic capacity and NO production in the inflammatory site $24 \mathrm{~h}$ after CLP, which may have contributed to the bacterial control and survival of animals. Moreover, studies reported that $\beta$-Lap induced antibacterial activity through the generation of $\mathrm{O}_{2}^{--}$and $\mathrm{H}_{2} \mathrm{O}_{2}[13,14]$. In addition, our study showed that $\beta$-Lap pretreatment modulates mononuclear cells into the peritoneal cavity increasing the recruitment of these cells. The recruiting of mononuclear cells of the peritoneal cavity by $\beta$-Lap apparently consists in macrophages, cells essential for the active process for the control of sepsis [41]. Collaborating with our data, studies conducted in the mouse model of wound healing found that the treatment with $\beta$-Lap for 22 days promoted macrophage proliferation and accelerated cicatrization [42]. Macrophages comprise a heterogeneous population of cells that can become polarized into distinct subpopulations displaying either a classically activated (M1) or alternatively activated (M2) profile [43]. While M1 macrophages are characterized by producing proinflammatory cytokines (TNF- $\alpha$, IL- $1 \beta$, IL- 6 , etc.), the profile M2 is involved in tissue repair and in the regulation of the excessive inflammatory response [43]. Mehta et al. evaluated in baboons with experimental peritonitis induced by an E. coli-laden fibrin clot the immunoinflammatory sequelae in sepsis and septic shock and observed that monocytes from baboons that died largely displayed the characteristics of classically activated M1 macrophages [44].

In this study, the prophylactic treatment with $\beta$-Lap mitigates the excessive release of TNF- $\alpha$, IL- $1 \beta$ in serum, and peritoneal cavity of animals 24 hours after CLP, suggesting a polarization to M2 phenotype, which is associated with the downregulation of nuclear factor kappa B (NF- $\kappa \mathrm{B}$ ) pathway that in sepsis promotes excessive release of IL-1 $\beta$ and $\mathrm{TNF} \alpha$, inflammatory cytokines central to the pathophysiology and partly involved in the pathogenesis of multiple organ failure [45]. In fact, previous studies in vitro and in vivo have demonstrated that $\beta$-Lap is able to inhibit the phosphorylation of protein tyrosine and NF- $\kappa \mathrm{B}$ activation $[16,46]$. Therefore, blockage in the production of these proinflammatory cytokines through inhibition of NF- $\kappa \mathrm{B}$ may prevent the excessive inflammatory reaction during sepsis [47].

In our model, we observed the reduction of $\mathrm{NO}$ in the serum of $\beta$-Lap-pretreated animals. Endothelial-derived NO dilates blood vessels by relaxing vascular smooth muscle and maintains microvascular homeostasis [48]. Although
$\mathrm{NO}$ is important for the regulation of blood pressure, its excessive augmentation can lead to severe hypotension and shock due to vascular instability and myocardial depression [49]. Thus, the anti-inflammatory and protective effect of $\beta$-Lap can be in part due to the inhibiting of systemic NO. In agreement, it was reported that in vitro, $\beta$-Lap inhibited the expression of iNOS, proinflammatory cytokines, and matrix metalloproteinases 3,8 , and 9 at messenger ribonucleic acid (mRNA) and protein levels in lipopolysaccharide- (LPS-) stimulated microglia, by inhibiting mitogen-activated protein kinase (MAPKs), via phosphatidylinositol 3 kinase/protein kinase B (PI3K/AKT), and nuclear factor kappa $\mathrm{B} /$ activator protein 1 (NF- $\kappa \mathrm{B} / \mathrm{AP}-1$ ) signaling pathways in LPS-stimulated microglia [16]. Furthermore, it also inhibited the neuroinflammation induced by systemic administration of LPS in an inflammation mouse model [16].

Another feature of sepsis is the excessive production of ROS associated with inflammation that leads to a condition of oxidative stress [32]. This oxidative imbalance promotes macromolecule damage, including lipid peroxidation and oxidation of proteins and DNA [49]. High serum MDA levels have been associated with severity and mortality in septic patients [50]. In the present study, the levels of MDA were reduced in serum and peritoneal fluid of animals pretreated and posttreated with $\beta$-Lap. Additionally, $\beta$-Lap also increased the antioxidant capacity of these treated animals. In agreement, $\beta$-Lap has been reported to positively regulate the signaling pathway of the antioxidant response element nuclear factor erythroid-2-related factor 2 (Nrf2)/antioxidant response element (ARE), an important mechanism in cellular defense against oxidative or electrophilic stress $[16,19,51]$. In LPS-stimulated BV2 microglial cells, it was observed that $\beta$-Lap increased Nrf2 binding to ARE and induced phase II antioxidant enzymes [16]. In doxorubicin-induced cardiotoxicity, the $\beta$-Lap elevated the nuclear accumulation of Nrf2 and upregulated the protein levels of glutathione in the heart, as well as the activity of cardiac superoxide dismutase (SOD), glutathione peroxidase (GPX), and catalase (CAT), improving the cardiac function of treated mice [51]. In patients with sepsis, the decreased antioxidant capacity is associated with death [52].

In our study, $\beta$-lapachone pretreatment at the dose $(50 \mathrm{mg} / \mathrm{kg}$ ) was able to prevent tissue damage caused by an exacerbated immune response and oxidative stress induced by sepsis. We also found that $\beta$-Lap posttreatment in lower doses, mainly $1 \mathrm{mg} / \mathrm{kg}$, increases the survival of septic animals and reduced the tissue damage by antioxidant mechanisms but did not alter the immune response of septic animals. Thus, these data, together, suggest that $\beta$-lapachone has both prophylactic and therapeutic effects, because even in low doses and in posttreatment after sepsis, this compound 


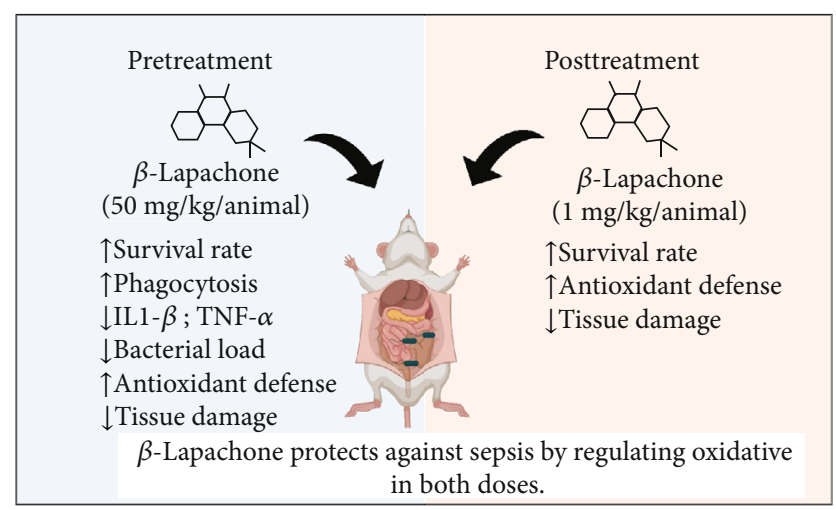

Figure 6: $\beta$-Lap enhanced survival and reduced organ damage and increases antioxidant defense in the CLP sepsis model in both doses (50 mg/kg; $1 \mathrm{mg} / \mathrm{kg}$ ).

was able to prevent animal death and tissue damage caused by the immune response to infection and oxidative processes.

\section{Conclusions}

In summary, taken together, our results reinforce, mainly the antioxidant capacity of $\beta$-Lap, and demonstrate for the first time its prophylactic and therapeutic effects in CLP-induced sepsis as summarized in Figure 6. $\beta$-Lap was able to increase the survival of septic animals by a mechanism involving immunomodulatory (increased mononuclear recruitment, phagocytosis, NO production, and bacterial killing), but mainly by an antioxidant mechanism. Further studies are needed to better elucidate the therapeutic mechanisms and ensure the safety of their clinical use.

\section{Data Availability}

All data generated or analyzed during this study are included in the article.

\section{Conflicts of Interest}

The authors declare no competing interests.

\section{Acknowledgments}

The authors are grateful for the financial support by the Brazilian's agencies: Conselho Nacional de Desenvolvimento Científico e Tecnológico (CNPq), Coordenação de Aperfeiçoamento de Pessoal de Nível Superior (CAPES), Fundação Amazônia Paraense de Amparo à Pesquisa (FAPESPA), and Pró-Reitoria de Pesquisa e Pós-graduação da Universidade Federal do Pará (PROPESP-UFPA). This work was funded by Federal University of Pará (UFPA). MCM and PRTR are grateful to $\mathrm{CNPq}$ for the $\mathrm{PQ}$ productivity scholarship.

\section{References}

[1] M. Singer, C. S. Deutschman, C. Seymour et al., "The third international consensus definitions for sepsis and septic shock (sepsis-3)," JAMA, vol. 315, pp. 801-810, 2016.
[2] L. L. dos Santos Barros, C. do Socorro Ferraz Maia, and M. C. Monteiro, "Fatores de risco associados ao agravamento de sepse em pacientes em Unidade de Terapia Intensiva," Cadernos Saúde Coletiva, vol. 24, pp. 388-396, 2016.

[3] C. Fleischmann, A. Scherag, N. K. J. Adhikari et al., "Assessment of global incidence and mortality of hospital-treated sepsis current estimates and limitations," American Journal of Respiratory and Critical Care Medicine, vol. 193, no. 3, pp. 259-272, 2016.

[4] C. Cao, M. Yu, and Y. Chai, "Pathological alteration and therapeutic implications of sepsis-induced immune cell apoptosis," Cell Death \& Disease, vol. 10, no. 10, article 782, 2019.

[5] H. Horiguchi, T. J. Loftus, R. B. Hawkins, et al., "Innate immunity in the persistent inflammation, immunosuppression, and catabolism syndrome and its implications for therapy," Frontiers in Immunology, vol. 9, pp. 1-20, 2018.

[6] R. de Souza Gomes, K. C. Navegantes-Lima, V. V. S. Monteiro et al., "Salivary gland extract from Aedes aegypti improves survival in murine polymicrobial sepsis through oxidative mechanisms," Cell, vol. 7, no. 11, 2018.

[7] Z. Zhang, H. Zhang, R. Chen, and Z. Wang, "Oral supplementation with ursolic acid ameliorates sepsis-induced acute kidney injury in a mouse model by inhibiting oxidative stress and inflammatory responses," Molecular Medicine Reports, vol. 17, pp. 7142-7148, 2018.

[8] G. Polat, R. A. Ugan, E. Cadirci, and Z. Halici, "Sepsis and septic shock: current treatment strategies and new approaches," The Eurasian Journal of Medicine, vol. 49, no. 1, pp. 53-58, 2017.

[9] K. C. Navegantes-Lima, V. V. S. Monteiro, S. L. de França Gaspar et al., "Agaricus brasiliensis mushroom protects against sepsis by alleviating oxidative and inflammatory response," Frontiers in Immunology, vol. 11, pp. 1-14, 2020.

[10] M. L. S. Queiroz, M. C. Valadares, C. O. Torello et al., "Comparative studies of the effects of Tabebuia avellanedae bark extract and $\beta$-lapachone on the hematopoietic response of tumourbearing mice," Journal of Ethnopharmacology, vol. 117, pp. 228235, 2008.

[11] Y. Yang, X. Zhou, X. M et al., “ $\beta$-lapachone suppresses tumour progression by inhibiting epithelial- to-mesenchymal transition in NQO1-positive breast cancers," Scientific Reports, vol. 7, article 2681, 2017.

[12] D. O. dos Anjos, E. S. S. Alves, V. T. Gonçalves et al., "Effects of a novel $\beta$-lapachone derivative on Trypanosoma cruzi: parasite death involving apoptosis, autophagy and necrosis," International Journal for Parasitology: Drugs and Drug Resistance, vol. 6, pp. 207-219, 2016.

[13] I. M. F. Cavalcanti, J. G. Pontes-Neto, P. O. Kocerginsky et al., "Antimicrobial activity of $\beta$-lapachone encapsulated into liposomes against meticillin-resistant Staphylococcus aureus and Cryptococcus neoformans clinical strains," Journal of Global Antimicrobial Resistance, vol. 3, pp. 103-108, 2015.

[14] F. S. Cruz, R. Docampo, and A. Boveris, "Generation of superoxide anions and hydrogen peroxide from beta-lapachone in bacteria," Antimicrobial Agents and Chemotherapy, vol. 14, pp. 630-633, 1978.

[15] C. S. Medeiros, N. T. Pontes-Filho, C. A. Camara et al., "Antifungal activity of the naphthoquinone betalapachone against disseminated infection with Cryptococcus neoformans var. neoformans in dexamethasone-immunosuppressed Swiss mice," Brazilian Journal of Medical and Biological Research, vol. 43, pp. 345-349, 2010. 
[16] E. J. Lee, H. M. Ko, Y. H. Jeong, E. M. Park, and H. S. Kim, " $\beta$-Lapachone suppresses neuroinflammation by modulating the expression of cytokines and matrix metalloproteinases in activated microglia," Journal of Neuroinflammation, vol. 12, article 133, 2015.

[17] M. M. Sitônio, C. H. R. de Carvalho Júnior, I. D. A. Campos et al., "Anti-inflammatory and anti-arthritic activities of 3,4dihydro-2,2-dimethyl-2H-naphthol[1,2-b]pyran-5,6-dione ( $\beta$-lapachone)," Inflammation Research, vol. 62, no. 1, pp. 107-113, 2013.

[18] D. O. Moon, Y. H. Choi, N. D. Kim, Y. M. Park, and G. Y. Kim, "Anti-inflammatory effects of $\beta$-lapachone in lipopolysaccharidestimulated BV2 microglia," International Immunopharmacology, vol. 7, pp. 506-514, 2007.

[19] J. Park, Y. Lee, J. Kim, H. Seo, and H. Kim, “ $\beta$-Lapachone increases phase II antioxidant enzyme expression via NQO1AMPK/PI3K-Nrf 2/ARE signaling in rat primary astrocytes," Free Radical Biology and Medicine, vol. 97, pp. 168-178, 2016.

[20] J. H. Lee, J. Cheong, Y. M. Park, and Y. H. Choi, “Down-regulation of cyclooxygenase- 2 and telomerase activity by $\beta$-lapachone in human prostate carcinoma cells," Pharmacological Research, vol. 51, pp. 553-560, 2005.

[21] S. C. Hooker, "Lomatiol. Part II. Its occurrence, constitution, relation to and conversion into lapachol. Also a synthesis of lapachol," Journal of the American Chemical Society, vol. 58, pp. 1181-1190, 1936.

[22] G. Schabbauer, "Polymicrobial sepsis models: CLP versus CASP," Drug Discovery Today Disease Models, vol. 9, pp. e17-e21, 2012.

[23] N. Phoolcharoen, S. Nilgate, O. Rattanapuntamanee, S. Limpongsanurak, and S. Chaithongwongwatthana, "A randomized controlled trial comparing ceftriaxone with cefazolin for antibiotic prophylaxis in abdominal hysterectomy," International Journal of Gynecology \& Obstetrics, vol. 119, no. 1, pp. 11-13, 2012.

[24] P. Rattanaumpawan, P. Werarak, A. Jitmuang, P. Kiratisin, and V. Thamlikitkul, "Efficacy and safety of de-escalation therapy to ertapenem for treatment of infections caused by extended-spectrum- $\beta$-lactamase-producing Enterobacteriaceae: an open-label randomized controlled trial," BMC Infectious Diseases, vol. 17, article 183, 2017.

[25] D. C. Nascimento, P. H. Melo, A. R. Pineros et al., "33 contributes to sepsis-induced long-term immunosuppression by expanding the regulatory T cell population," Nature Communications, vol. 8, article 14919, 2017.

[26] S. J. R. Bonatto, A. Folador, J. Aikawa et al., "Lifelong exposure to dietary fish oil alters macrophage responses in Walker 256 tumor-bearing rats," Cellular Immunology, vol. 231, pp. 5662, 2004.

[27] P. R. T. Romão, S. G. Fonseca, J. S. Hothersall, A. A. NoronhaDutra, S. H. Ferreira, and F. Q. Cunha, "Glutathione protects macrophages andLeishmania majoragainst nitric oxidemediated cytotoxicity," Parasitology, vol. 118, no. 6, pp. 559566, 1999.

[28] S. Percario, A. Vital, and F. Jablonka, "Dosagem do malondialdeido," Newslab, vol. 2, no. 6, pp. 46-50, 1944.

[29] N. J. Miller, C. Rice-Evans, M. Davies, V. Gopinathan, and A. Milner, "A novel method for measuring antioxidant capacity and its application to monitoring the antioxidant status in premature neonates," Clinical Science, vol. 84, no. 4, pp. 407412, 1993.
[30] K. J. Ahn, H. S. Lee, K. B. Bai, and C. W. Song, "Enhancement of radiation effect using beta-lapachone and underlying mechanism," Radiation Oncology Journal, vol. 31, pp. 5765, 2013.

[31] J. J. Pink, S. M. Planchon, C. Tagliarino, M. E. Varnes, D. Siegel, and D. A. Boothman, "NAD (P)H: quinone oxidoreductase activity is the principal determinant of beta-lapachone cytotoxicity," The Journal of Biological Chemistry, vol. 257, pp. 5416-5424, 2000.

[32] H. N. Kung, T. Y. Weng, Y. L. Liu, K. S. Lu, and Y. P. Chau, "Sulindac compounds facilitate the cytotoxicity of $\beta$-lapachone by up-regulation of $\mathrm{NAD}(\mathrm{P}) \mathrm{H}$ quinone oxidoreductase in human lung cancer cells," PLoS One, vol. 9, no. 2, article e88122, 2014.

[33] E. A. Bey, M. S. Bentle, K. E. Reinicke et al., "An NQO1- and PARP-1-mediated cell death pathway induced in nonsmallcell lung cancer cells by beta-lapachone," Proceedings of the National Academy of Sciences, vol. 104, pp. 11832-11837, 2007.

[34] M. E. F. A. G. Oliveira, E. C. G. M. Silva, C. A. Câmara, I. A. Souza, and R. V. S. Amorim, "Evaluation of acute toxicity of $\beta$-lapachone associated with chitosan as a cytoprotective agent," Jornal Brasileiro de Patologia e Medicina Laboratorial, vol. 54, pp. 279-287, 2018.

[35] C. Rosales, N. Demaurex, C. A. Lowell, and E. Uribe-Querol, "Neutrophils: their role in innate and adaptive immunity," Journal of Immunology Research, vol. 2016, Article ID 1469780, 2 pages, 2016.

[36] M. Bosmann and P. A. Ward, "The inflammatory response in sepsis,” Trends in Immunology, vol. 34, pp. 129-136, 2012.

[37] X. Shen, K. Cao, J. Jiang, W. Guan, and J. F. du, "Neutrophil dysregulation during sepsis: an overview and update," Journal of Cellular and Molecular Medicine, vol. 21, no. 9, pp. 16871697, 2017.

[38] K. Yonekawa and J. M. Harlan, “Targeting leukocyte integrins in human diseases," Journal of Leukocyte Biology, vol. 77, pp. 129-140, 2005.

[39] M. J. Foulkes, F. H. Tolliday, K. M. Henry, S. A. Renshaw, and S. Jones, "Evaluation of the anti-inflammatory effects of synthesised tanshinone I and isotanshinone I analogues in zebrafish," PLoS One, vol. 15, no. 10, article e0240231, 2020.

[40] E. Moreno, J. Schwartz, E. Larrea et al., “Assessment of $\beta$-lapachone loaded in lecithin-chitosan nanoparticles for the topical treatment of cutaneous leishmaniasis in L. major infected BALB/c mice," Nanomedicine, vol. 11, no. 8, pp. 2003-2012, 2015.

[41] Y. Liu, X. Zou, Y. Chai, and Y. Yao, "Macrophage polarization in inflammatory diseases," Journal of Biological Sciences, vol. 10, pp. 520-529, 2014.

[42] S. Fu, Y. Chau, K. Lu, and H. Kung, “ $\beta$-Lapachone accelerates the recovery of burn-wound skin," Histology and Histopathology, vol. 26, pp. 905-914, 2011.

[43] K. C. Navegantes, R. de Souza Gomes, P. A. T. Pereira, P. G. Czaikoski, C. H. M. Azevedo, and M. C. Monteiro, "Immune modulation of some autoimmune diseases: the critical role of macrophages and neutrophils in the innate and adaptive immunity," Journal of Translational Medicine, vol. 15, no. 1, article 36, 2017.

[44] A. Mehta, R. Brewington, M. Chatterji et al., "Infectioninduced modulation of M1 and M2 phenotypes in circulating monocytes: role in immune monitoring and early prognosis of sepsis," Shock, vol. 22, pp. 423-430, 2004. 
[45] Y. Cheng, T. N. Marion, X. Cao, W. Wang, and Y. Cao, "Park 7: a novel therapeutic target for macrophages in sepsisinduced immunosuppression," Frontiers in Immunology, vol. 9, article 2632, 2018.

[46] C. H. Tseng, C. M. Cheng, C. C. Tzeng, S. I. Peng, C. L. Yang, and Y. L. Chen, "Synthesis and anti-inflammatory evaluations of $\beta$-lapachone derivatives," Bioorganic \& Medicinal Chemistry, vol. 21, pp. 523-531, 2013.

[47] S. F. Liu and A. B. Malik, "NF- $\kappa$ B activation as a pathological mechanism of septic shock and inflammation," American Journal of Physiology Lung Cellular and Molecular Physiology, vol. 290, no. 4, pp. L622-L645, 2006.

[48] K. A. Kirkeboen and O. A. Strand, "The role of nitric oxide in sepsis - an overview," Acta Anaesthesiologica Scandinavica, vol. 43, no. 3, pp. 275-288, 1999.

[49] K. Mantzarlis, V. Tsolaki, and E. Zakynthinos, "Role of oxidative stress and mitochondrial dysfunction in sepsis and potential therapies," Oxidative Medicine and Cellular Longevity, vol. 2017, Article ID 5985209, 10 pages, 2017.

[50] L. Lorente, M. M. Martín, P. Abreu-gonzález et al., "Sustained high serum malondialdehyde levels are associated with severity and mortality in septic patients," Critical Care, vol. 17, no. 6, article R290, 2013.

[51] S. Nazari Soltan Ahmad, D. Sanajou, A. Kalantary-Charvadeh et al., " $\beta$-LAP achone ameliorates doxorubicin-induced cardiotoxicity via regulating autophagy and Nrf 2 signalling pathways in mice," Basic \& Clinical Pharmacology \& Toxicology, vol. 126, no. 4, pp. 364-373, 2020.

[52] H. F. Galley, "Bench-to-bedside review: targeting antioxidants to mitochondria in sepsis," Critical Care, vol. 14, no. 4, pp. 230-239, 2010. 